\title{
Prevalence and molecular detection of fluoroquinolone-resistant genes (qnrA and qnrS) in Escherichia coli isolated from healthy broiler chickens
}

\author{
Shahin Mahmud, K. H. M. Nazmul Hussain Nazir and Md. Tanvir Rahman \\ Department of Microbiology and Hygiene, Faculty of Veterinary Science, Bangladesh Agricultural University, \\ Mymensingh 2202, Bangladesh. \\ Corresponding author: Md. Tanvir Rahman, e-mail: tanvirahman@bau.edu.bd \\ Co-authors: SM: shahindvm38@gmail.com, KHMNHN: nazir@bau.edu.bd \\ Received: 16-08-2018, Accepted: 09-11-2018, Published online: 24-12-2018
}

doi: 10.14202/vetworld.2018.1720-1724 How to cite this article: Mahmud S, Nazir KHMNH, Rahman MT (2018) Prevalence and molecular detection of fluoroquinolone-resistant genes ( $q n r A$ and qnrS) in Escherichia coli isolated from healthy broiler chickens, Veterinary World, 11(12): 1720-1724.

\begin{abstract}
Aim: The present study was carried out to determine the prevalence and molecular detection of fluoroquinolone-resistant Escherichia coli carrying qnrA and qnrS genes in healthy broiler chickens in Mymensingh, Bangladesh, and also to identify the genes responsible for such resistance.

Materials and Methods: A total of 65 cloacal swabs were collected from apparently healthy chickens of 0-14 days ( $\mathrm{n}=23$ ) and 15-35 days $(n=42)$ old. The samples were cultured onto Eosin Methylene Blue Agar, and the isolation and identification of the E. coli were performed based on morphology, cultural, staining, and biochemical properties followed by polymerase chain reaction (PCR) targeting $E$. coli $16 \mathrm{~S}$ rRNA genes. The isolates were subjected to antimicrobial susceptibility test against five commonly used antibiotics under fluoroquinolone (quinolone) group, namely gatifloxacin, levofloxacin, moxifloxacin, ofloxacin, and pefloxacin by disk diffusion method. Detection of $q n r A$ and $q n r S$ genes was performed by PCR.

Results: Among the 65 cloacal samples, 54 (83.08\%) were found to be positive for $E$. coli. Antibiotic sensitivity test revealed that, of these 54 isolates, $18(33.33 \%)$ were found to be resistant to at least one fluoroquinolone antibiotic. The highest resistance was observed against pefloxacin (61.11\%). By PCR, of 18 E. coli resistant to fluoroquinolone, $13(72.22 \%)$ were found to be positive for the presence of $q n r S$. None of the isolates were found positive for $q n r A$.
\end{abstract}

Conclusion: Fluoroquinolone-resistant E. coli harboring qnrS genes is highly prevalent in apparently healthy broiler chickens and possesses a potential threat to human health.

Keywords: Escherichia coli, healthy broiler chickens, polymerase chain reaction, qnrA, qnrS, quinolone resistance.

\section{Introduction}

Antibiotic resistance is an ever-increasing multinational public health crisis. It causes an estimated 700,000 deaths each year across the world [1]. Modern food animal production depends on the use of large amount of antibiotics for disease control and agricultural purposes, particularly for growth enhancement. This increased use of antibiotics is known to be a major factor for the development of antibiotic resistance in bacteria. Antibiotic-resistant bacterial species are widely distributed in both healthy and diseased animals and birds. Diseases caused by antibiotic-resistant bacteria are very difficult to treat. Poultry eggs and meats are major sources of human dietary protein. In Bangladesh poultry is raised in close association with human. From healthy birds, these antibiotic-resistant bacteria can spread directly to human

Copyright: Mahmud, et al. Open Access. This article is distributed under the terms of the Creative Commons Attribution 4.0 International License (http://creativecommons.org/licenses/ by/4.0/), which permits unrestricted use, distribution, and reproduction in any medium, provided you give appropriate credit to the original author(s) and the source, provide a link to the Creative Commons license, and indicate if changes were made. The Creative Commons Public Domain Dedication waiver (http:// creativecommons.org/publicdomain/zero/1.0/) applies to the data made available in this article, unless otherwise stated. or indirectly through contaminated egg and meat, for example, through the food chain to cause severe health problems [2]. Escherichia coli is a Gram-negative enteric bacterium of the family Enterobacteriaceae. They are one of the main species of bacteria that live in the lower intestines of warm-blooded animals and birds. While most of the E. coli strains are non-pathogenic, some of them can cause a variety of intestinal and extraintestinal infections in men, animals, and poultry [3]. In the poultry industry, colibacillosis, a disease caused by $E$. coli, significantly contributes to increased mortality and economic losses [4].

Fluoroquinolone (quinolones) antibiotics are a group of synthetic broad-spectrum bactericidal chemical agents having a bicyclic core structure related to 4-quinolone. They were introduced first in the form of nalidixic acid in the 1960s. This fully synthetic agent was discovered as a by-product of research on antimalarial drugs. Fluoroquinolones are also one of the most commonly used antibiotics, particularly in poultry. Fluoroquinolones interfere bacterial DNA synthesis by inhibiting topoisomerase class enzymes, namely DNA gyrase (topoisomerase II) in Gram-negative bacteria and topoisomerase IV in Gram-positive microorganisms [5]. Resistance against fluoroquinolone occured is primarily due to activities of products of genes such 
as $g y r A, g y r B, \operatorname{par} C, q n r A$, and $q n r S$ which interfere the bacterial DNA synthesis. Since the 1990s, reports on the occurrence of fluoroquinolone-resistant $E$. coli from humans as well as animal have increased significantly [6-8]. Fluoroquinolone-resistant $E$. coli isolates have become a major problem in infection control and treatment worldwide.

In Bangladesh, few previous studies were carried out to investigate the occurrence and characterization of fluoroquinolone- and quinolone-resistant $E$. coli in human [7,8]. Quinolone-resistant E. coli has also been detected in healthy cattle and other animals from many other countries $[9,10]$. Recently, in a study in Bangladesh, quinolone-resistant E. coli was detected from apparently healthy cattle [11]. As fluoroquinolones are of major therapeutic importance in human medicine, quinolone-resistant $E$. coli is of great public health concern. Bangladesh is one of the most densely populated countries of the world. The livestock and poultry population, here, are also noticeable. Due to the close contact of human with poultry, there is a great chance for the transmission of antibiotic-resistant $E$. coli from poultry to human.

To the best of our knowledge, no work has yet been reported in Bangladesh on fluoroquinolone resistant in $E$. coli in healthy broiler chickens targeting the detection of qnrA and $q n r S$ genes by polymerase chain reaction (PCR). The present study was carried out to determine the occurrence of fluoroquinolone-resistant E. coli in healthy broiler in Mymensingh, Bangladesh. In addition, the genes responsible for such resistance were also identified by PCR-based approach.

\section{Materials and Methods}

\section{Ethical approval}

No ethical approval was required although all applicable international, national, and institutional guidelines for the care and use of animals were followed during sample collection.

\section{Collection of samples}

A total of 65 cloacal swab samples were collected randomly from apparently healthy broiler chickens sold at Bangladesh Agricultural University (BAU), Mymensingh, and surrounding area. Among these 65 samples, 23 originated from BAU poultry farm, 5 from Kawatkhali market, 15 from Sesmore market, and 22 from KR market, BAU. Samples were collected maintaining sterile condition and categorized into two age groups: 0-14 days and 15-35 days depending on the age of the birds.

\section{Isolation and identification of $E$. coli}

Isolation and identification of $E$. coli from the collected cloacal swab were done based on morphology, staining, cultural, and biochemical characteristics [12]. Confirmation of the E. coli isolates was done by PCR. DNA for the PCR was extracted from pure culture by boiling method. In brief, $100 \mu 1$ of deionized water was taken into an Eppendorf tube. A pure bacterial colony from overnight culture on $37^{\circ} \mathrm{C}$ of Eosin Methylene Blue Agar was gently mixed with deionized water. The tube was then transferred into boiling water and boiled for $10 \mathrm{~min}$, then immediately transferred to ice for cold shock for about $10 \mathrm{~min}$, and finally centrifuged at $10,000 \mathrm{rpm}$ for $10 \mathrm{~min}$. Supernatant from each tube was collected and used as PCR DNA template. The extracted DNA was stored at $-20^{\circ} \mathrm{C}$ until use. PCR for E. coli $16 \mathrm{~S}$ rRNA gene was performed using primers ECO-1 and ECO-2 (Table-1) according to the standard protocol $[13,14]$.

\section{Antibiotic sensitivity test}

The isolated E. coli isolates were subjected to antibiotic sensitivity test against five commonly used fluoroquinolone, i.e., gatifloxacin $(5 \mu \mathrm{g})$, levofloxacin $(5 \mu \mathrm{g})$, moxifloxacin $(5 \mu \mathrm{g})$, ofloxacin $(5 \mu \mathrm{g})$, and pefloxacin $(5 \mu \mathrm{g})$, following disc diffusion method, as described by Bauer et al. [15]. All the tests were performed on Mueller-Hinton media with a concentration of bacteria equivalent to 0.5 McFarland standards. Results of the antibiotic sensitivity tests were recorded as sensitive, intermediately sensitive, or resistant, and the zone of growth inhibition was compared with the zone size interpretative tables provided by the Clinical and Laboratory Standards Institute [16].

\section{Molecular detection of qnrA and qnrS genes}

Molecular detection of $E$. coli carrying fluoroquinolone-resistant genes ( $q n r A$ and $q n r S$ ) was performed by PCR [14]. For this purpose, DNA was extracted from E. coli that was found resistant to quinolone phenotypically by the boiling method as described above. The primers used for the detection of $q n r A$ and $q n r S$ are presented in Table-1 $[13,14]$.

\section{Results}

Isolation of $E$. coli

Among the 65 cloacal samples analyzed, $54(83.08 \%)$ were found to be positive for E. coli

Table-1: Primers for the detection of E. coli $16 \mathrm{~S}$ rRNA gene, qnrS and qnrS genes.

\begin{tabular}{lllcr}
\hline Primer name & Target gene & Primer sequence & Amplicon size (bp) & References \\
\hline ECO-1 & 16S rRNA gene & 5'-GACCTCGGTTAGTTCACAGA-3' & 585 & {$[13]$} \\
ECO-2 & & 5'-CACACGCTGACGCTGACCA-3' & & 516 \\
qnrAF & fnrA & 5'-ATTCTCACGCCAGGATTG-3' & & {$[14]$} \\
qnrAR & & 5'-GATCGGCAAAGGTTAGGTCA-3' & 417 & {$[14]$} \\
qnrSF & qnrS & 5'-ACGACATTCGTCAACTGCAA-3' & 4 & \\
qnrSR & & 5'-TAAATTGGCACCCTGTAGGC-3' & & \\
\hline
\end{tabular}

E. coli=Escherichia coli 
(Table-2). On age basis, the highest prevalence of $E$. coli was found in 15-35-day-old healthy broiler chickens $(88.07 \%)$, while the prevalence was $73.91 \%$ in 0-14-day-old birds.

\section{Phenotypic detection of fluoroquinolone-resistant E. coli}

All the isolates of $E$. coli $(\mathrm{n}=54)$ were screened for antibiogram profile against the five fluoroquinolone group of antibiotics. Among these, 18 (33.33\%) isolates were found resistant to at least one fluoroquinolone antibiotic (Figure-1). To be sure that these are E. coli, PCR was done, and all these 18 isolates were found positive for $E$. coli $16 \mathrm{~S}$ rRNA genes (data were not shown).

From Table-3, it is evident that, in general, fluoroquinolone resistance was higher in $E$. coil isolated from the older birds, i.e., 15-35 days old as compared to younger birds of 0-14 days old. The overall antibiogram profile of the isolated $E$. coli against vari ous groups of quinolone groups of antibiotics is presented in Table-4. From the antibiogram profile, it was observed that the highest resistance was found against pefloxacin $(61.11 \%)$, while the levofloxacin showed less percentage of resistance $(22.22 \%)$.

\section{Molecular detection of qnrA and qnrS genes}

Eighteen E. coli that showed phenotypically resistant to one or more quinolone group of antibiotics were PCR screened for the detection of $q n r A$ and $q n r S$ genes. None of the isolates were found positive for $q n r A$ (prevalence $0 \%$ ). On the other hand, among 18 isolates, 13 (prevalence $72.22 \%$ ) were found positive (Table-5) for $q n r S$ gene amplifying 417-bp amplicon (Figure-2).

On age bases, the prevalence of $q n r S$ was found higher in older birds, i.e., 15-35-day-old birds compared to younger 0-14-day-old birds.

\section{Discussion}

Antibiotic-resistant bacteria are of great public health concern since they possess a significant threat to human and animal health. E. coli is ubiquitous in nature and found commonly as intestinal flora of animal and birds. Many of these E. coli are pathogenic and zoonotic in nature. Once they become antibiotic resistant, it is very difficult to treat the disease caused by them. Increasing bacterial resistance to quinolone antibiotics is apparent in humans, livestock, and poultry. The potential source of these resistant bacteria for human is livestock and poultry or their products entering the human food chain.

Fluoroquinolones are broad-spectrum antimicrobial agents, used extensively in poultry [17]. Fluoroquinolone-resistant genes such as $g y r A, g y r B$, and $\operatorname{parC}$ are located in chromosome, while gnr genes are located in plasmid. In this study, we focused on this plasmid-mediated quinolone resistance since these $q n r$ genes containing plasmid have potentiality for transfer of resistance to other bacteria horizontally [18]. In addition, these plasmid harboring $q n r$ genes may also encode extended-spectrum beta-lactamases such as CTX-M, SHV, and TEM type [19].

In this study, about $83.03 \%$ apparently healthy broiler chickens were found to be positive for the presence of $E$. coli in their cloacal swabs (Table-2). Since E. coli is a normal inhabitant of birds' lower gastrointestinal tract, it was not unexpected to find them in higher percentage in the cloacal samples. There are previous reports on $60-82 \%$ prevalence of E. coli in apparently healthy chickens in Mymensingh, Bangladesh [20,21]. These observed variations in the prevalence of $E$. coli in healthy chickens could be due to variations in the hygienic status of farms, farm biosecurity, ventilation system, sample size, and location of the study area. In this study, we observed a higher

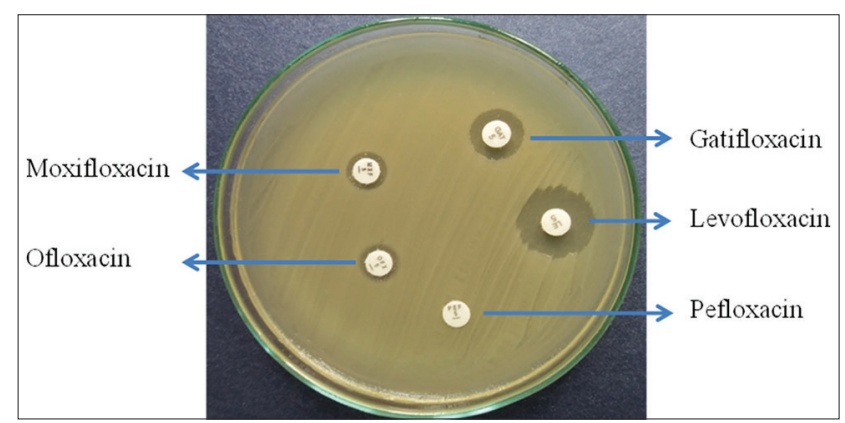

Figure-1: Antibiogram profile of a multidrug-resistant Escherichia coli isolated from the cloacal swab of an apparently healthy broiler chicken showing resistance to moxifloxacin, ofloxacin and pefloxacin and sensitive to gatifloxacin and levofloxacin.

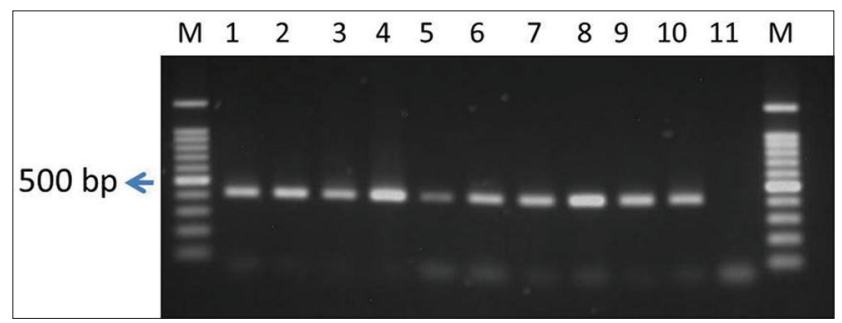

Figure-2: Polymerase chain reaction amplification of qnrS gene of Escherichia coli isolated from apparently healthy broiler chicken. M - 100 bp size DNA marker; lanes 1-9 - Representative E. coli, lane 10 - Positive control and lane 11 - Negative control

Table-2: Prevalence of $E$. coli in the cloacal swab of apparently healthy broiler chickens.

\begin{tabular}{lccc}
\hline Age groups (days) & Number of samples tested (n) & $\begin{array}{c}\text { Number of samples found positive for } \\
\text { E. coli (n) }\end{array}$ & Prevalence (\%) \\
\hline $0-14$ & 23 & 17 & 73.91 \\
$15-35$ & 42 & 37 & 88.07 \\
Total & 65 & 54 & 83.08 \\
\hline
\end{tabular}

E. coli=Escherichia coli 
Table-3: Antibiogram profile of the $E$. coli isolated from the cloacal swab of apparently healthy broiler chickens against the quinolone antibiotics.

\begin{tabular}{|c|c|c|c|c|c|c|c|}
\hline \multirow[t]{2}{*}{ Age groups (days) } & \multirow[t]{2}{*}{ Number of $E$. coli tested $(n)$} & \multirow[t]{2}{*}{ Sensitivity pattern } & \multicolumn{5}{|c|}{$\begin{array}{c}\text { Sensitivity pattern on number of } \\
E . \text { coli against fluoroquinolone } \\
\text { antibiotics }\end{array}$} \\
\hline & & & Gati & Levo & Moxi & Peflo & Oflo \\
\hline \multirow[t]{3}{*}{$0-14$} & 06 & Sensitive & 1 & 3 & 2 & 2 & 3 \\
\hline & & Intermediate & 2 & 2 & 1 & 0 & 1 \\
\hline & & Resistant & 3 & 1 & 3 & 4 & 2 \\
\hline \multirow[t]{3}{*}{$15-35$} & 12 & Sensitive & 5 & 6 & 2 & 1 & 2 \\
\hline & & Intermediate & 3 & 3 & 3 & 4 & 2 \\
\hline & & Resistant & 4 & 3 & 7 & 7 & 8 \\
\hline
\end{tabular}

Gati=Gatifloxacin, Levo=Levofloxacin, Moxi=Moxifloxacin, Peflo=Pefloxacin, Oflo=Ofloxacin, E. coli=Escherichia coli

Table-4: The overall prevalence of fluoroquinolone-resistant E. coli.

\begin{tabular}{lcrr}
\hline Name of fluoroquinolone antibiotics & \multicolumn{3}{c}{ Number of isolates found resistant } \\
\cline { 2 - 3 } & \multicolumn{2}{c}{ Age of birds } & Total (\%) \\
\cline { 2 - 3 } & $\mathbf{0 - 1 4}$ days & $\mathbf{1 5 - 3 5}$ days & $7(38.89)$ \\
\hline Gatifloxacin & 3 & 4 & $4(22.22)$ \\
Levofloxacin & 1 & 3 & $10(50.00)$ \\
Moxifloxacin & 3 & 7 & $11(61.11)$ \\
Pefloxacin & 4 & 8 & $10(55.00)$ \\
Ofloxacin & 2 & 7 & \\
\hline
\end{tabular}

E. coli=Escherichia coli

Table-5: Prevalence of qnrS genes in the fluoroquinolone-resistant E. coli as detected by PCR.

\begin{tabular}{lccc}
\hline $\begin{array}{l}\text { Age } \\
\text { group (days) }\end{array}$ & $\begin{array}{c}\text { Number of } \boldsymbol{E} \text {. coli } \\
\text { tested by PCR }\end{array}$ & $\begin{array}{c}\text { Number of } \boldsymbol{E} \text {. coli found positive } \\
\text { for qnrA (prevalence) }\end{array}$ & $\begin{array}{c}\text { Number of } \boldsymbol{E} \text {. coli found positive for } \\
\text { qnrS (prevalence) }\end{array}$ \\
\hline $0-14$ & 6 & $0(0 \%)$ & $4(66.66 \%)$ \\
$15-35$ & 12 & $0(0 \%)$ & $9(81.82 \%)$ \\
Total & 18 & $0(0 \%)$ & $13(72.22 \%)$ \\
\hline
\end{tabular}

E. coli=Escherichia coli, $\mathrm{PCR}=$ Polymerase chain reaction

prevalence of $E$. coli in older birds as compared to younger bird as supported by earlier reports [22]. This observed a higher prevalence of $E$. coli in older birds might be due to their longer duration of exposure to unhygienic environment, unhealthy management, poor feeding, and watering as compared to younger birds.

Fluoroquinolone antibiotics are widely used in poultry to treat diseases caused by E. coli. Antibiogram profile observed in this study revealed $33.33 \%$ E. coli as resistant to one or more fluoroquinolone group of antibiotics phenotypically. This resistance was higher in older birds as compared to younger birds. It is alarming that, here, we found some of the isolates as multidrug-resistant (MDR) showing resistant against two or three fluoroquinolone group of antibiotic (Figure-1). In a report from Czech Republic, the resistance of $E$. coli of poultry isolates to quinolones ranged from $53 \%$ to $73 \%$. Among these resistant phenotypes, resistant genes were detected in $58 \%$ of the tested strains [4]. Among the quinolone-resistant genes, qnrA and $q n r S$ are important. In this study, among the resistant phenotype, about $72.22 \%$ isolates were found positive for $q n r S$ gene, while none was found positive for qnrA. Earlier in Sweden, an increased quinolone-resistant $E$. coli was noted in broiler population, despite the lack of a known selective pressure [23]. They also detected quinolone-resistant $q n r S$ gene in $E$. coli strain isolated from broiler.

Due to their high efficacy, quinolones are widely prescribed antibiotic classes for the treatment of human infections caused by bacteria and have been considered critically important for human health by the WHO [24]. The presence of high level of fluoroquinolone-resistant $E$. coli in healthy broiler chicken as detected in this study is, therefore, very important from the public health point of view. Since human can get these resistant isolates from poultry, the use of fluoroquinolones in poultry has to be monitored very carefully.

\section{Conclusion}

The present study reveals the occurrence of fluoroquinolone-resistant E. coli in healthy broiler. Some of the isolates are MDR. This is the first report of the detection of $q n r S$ gene in E. coli isolated from healthy broiler chickens in Bangladesh which are resistant to fluoroquinolone group of antibiotics. From poultry, these resistant bacteria can be transfered to human through the food chain. It is now time to be careful in 
the use of fluoroquinolone and quinolone group antibiotics in poultry in Bangladesh.

\section{Authors' Contributions}

MTR and KHMNHN: Designed the study. SM did laboratory work and assisted by MTR and KHMNHN. MTR and SM prepared the manuscript and analyzed the data with the help of KHMNHN. All authors read and approved the final manuscript.

\section{Acknowledgments}

We want to thank the Bangladesh Agricultural University Research System and the University Grants Commission (UGC) of Bangladesh (Project No. 2015/254/UGC) for the support to carry out the study.

\section{Competing Interests} interests.

The authors declare that they have no competing

\section{References}

1. Institute of Medicine. (2010) Antibiotic Resistance: Implications for Global Health and Novel Intervention Strategies. The National Academies Press, Washington, DC.

2. Chika, E., Charles, E., Ifeanyichukwu, I. and Michael, A. (2018) First detection of fox-1 AmpC $\beta$-lactamase gene expression among Escherichia coli isolated from abattoir samples in Abakaliki, Nigeria. Oman Med. J., 33(3): 243-249.

3. Todar, K. (2007) Pathogenic E. coli. Online Textbook for Bacteriology. Available from: http://www.textofbacteriology.net/e.coli.html. Accessed on 18-06-2009.

4. Gross, W.G. (1994) Diseases due to Escherichia coli in poultry. In: Gyles, C.L., editor. Escherichia coli in Domestic Animals and Humans. CAB International, Wallingford, United Kingdom. p237-259.

5. Hricová, M., Röderová, M., Pudová, V., Hanulík, V., Halová, D., Julínková, P., Dolejská, M., Papoušek, I. and Bardoň, J. (2017) Quinolone-resistant Escherichia coli in poultry farming. Cent. Eur. J. Public Health, 25(2): 163-167.

6. Jurado, S., Orden, J.A., Horcajo, P., Fuente, R.D.L., RuizSanat-Quiteria, J.A., MartínezPulgarin, S. and DomínguezBernal, G. (2008) Characterization of fluoroquinolone resistance in Escherichia coli strains from ruminants. J. Vet. Diagn. Invest., 20(3): 342-345.

7. Akter, F., Amin, M.R., Osman, K.T., Anwar, M.N., Karim, M.M. and Hossain, M.A. (2011) Ciprofloxacinresistant Escherichia coli in hospital wastewater of Bangladesh and prediction of its mechanism of resistance. World J. Microbiol. Biotechnol., 28(3): 827-834.

8. Talukdar, P.K., Rahman, M., Rahman, M., Nabi, A., Islam, Z., Hoque, M.M., Endtz, H.P. and Islam, M.A. (2013) Antimicrobial resistance, virulence factors and genetic diversity of Escherichia coli isolates from household water supply in Dhaka, Bangladesh. PLoS One, 8(4): e61090.

9. Todorović, D., Velhner, M., Grego, E., Vidanović, D., Milanov, D., Krnjaić, D. and Kehrenberg, C. (2017) Molecular characterization of multidrug-resistant Escherichia coli isolates from bovine clinical mastitis and pigs in the Vojvodina Province, Serbia. Microb. Drug Resist., 24(1): 95-103.
10. Duse, A., Wallera, K.P., Emanuelson, U., Unnerstada, H.E., Perssona, Y., Bengtssona, B. (2015) Occurrence and spread of quinolone resistant Escherichia coli on dairy farms. Appl. Environ. Microbiol., 82(13): 3765-3773.

11. Mamun, M.M., Hassan, J., Nazir, K.H.M.N.H., Islam, M.A., Zesmin, K., Rahman, M.B. and Rahman, M.T. (2017) Prevalence and molecular detection of quinolone-resistant $E$. coli in rectal swab of apparently healthy cattle in Bangladesh. Int. J. Trop. Dis. Health, 24(2): 1-7.

12. Begum, F., Islam, M.M., Sohidullah, M., Kabir, S.M.L., Islam, M. and Rahman, M.T. (2016) Molecular identification and antibiogram profiles of Escherichia coli isolated from apparently healthy and diarrheic goats. Bangladesh $J$. Vet. Med., 14(2): 203-208.

13. Schippa, S., Iebba, V., Barbato, B., Nardo, G.D., Totino, V., Checchi, M.P., Longhi, C., Maiella, G., Cucchiara, S. and Conte, M.P. (2010) A distinctive 'microbial signature' in celiac pediatric patients. BMC Microbiol., 10(1): 175.

14. Robicsek, A., Strahilevitz, J., Sahm, D.F., Jacoby, G.A. and Hooper, D.C. (2006) Prevalence in ceftazidime-resistant Enterobacteriaceae isolates from the United States. Antimicrob. Agents Chemother., 50(8): 2872-2874.

15. Bauer, A.W., Kirby, W.M., Sherris, J.C. and Turck, M. (1966) Antibiotic susceptibility testing by a standardized single disk method. Am. J. Clin. Pathol., 45(4): 493-496.

16. Clinical and Laboratory Standards Institute. (2013) Performance Standards for Antimicrobial Disk Susceptibility Tests; Approved Standard-Eleventh Edition. CLSI Document M02-A11. Clinical and Laboratory Standards Institute, Wayne, PA.

17. Benameur, Q., Tali-Maamar, H., Assaous, F., Guettou, B., Benklaouz, M., Rahal, K. and Ben-Mahdi, M.H. (2018) Characterization of quinolone-resistant Enterobacteriaceae strains isolated from poultry in Western Algeria: First report of qnrS in Enterobacter cloacae. Vet. World, 11(4): 469-473.

18. Piekarska, K., Rzeczkowska, M., Zacharczuk, K., Chróst, A., Januszkiewicz, A., Bareja, E., Olak, M. and Gierczyński, R. (2012) Prevalence of $q n r$ genes in clinical Enterobacteriaceae non-susceptible to fluoroquinolone in Poland. Med. Dosw. Mikrobiol., 64(3): 211-29.

19. Jacoby, G.A., Walsh, K.E., Mills, D.M., Walker, V.J., Oh, H., Robicsek, A. and Hooper, D.C. (2006) QnrB another plasmid-mediated gene for quinolone resistance. Antimicrob. Agents Chemother., 50(4): 1178-1182.

20. Jakaria, A.T.M., Islam, M.A. and Khatun, M.M. (2012) Prevalence, characteristics and antibiogram profiles of Escherichia coli isolated from apparently healthy chickens in Mymensingh, Bangladesh. Microbes Health, 1(1): 27-29.

21. Hossain, M.T., Siddique, M.P., Hossain, F.M.A., Zinnah, M.A., Hossain, M.M., Alam, M.K., Rahman, M.T. and Choudhury, K.A. (2008) Isolation, identification, toxin profile and antibiogram of Escherichia coli isolated from broilers and layers in Mymensingh district of Bangladesh. Bangladesh J. Vet. Med., 6(1): 1-5.

22. Hassan, J., Parvej, M.S., Rahman, M.B., Khan, M.S.R., Rahman, M.T., Kamal, T. and Nazir, K.H.M. N.H. (2014) Prevalence and characterization of Escherichia coli from rectal swab of apparently healthy cattle in Mymensingh, Bangladesh. Microbes Health, 3(1): 12-14.

23. Börjesson, S., Guillard, T., Landén, A., Bengtsson, B. and Nilsson, O. (2015) Introduction of quinolone-resistant Escherichia coli to Swedish broiler population by imported breeding animals. Vet. Microbiol., 194: 74-78.

24. WHO. (2007) The World Health Report 2007-a Safe Future: Global Public Health Security in the $21^{\text {st }}$ Century. WHO, Geneva. 